\title{
Correction to: RIP1 protects melanoma cells from apoptosis induced by BRAF/MEK inhibitors
}

Fu Xi Lei ${ }^{1,2}$, Lei Jin ${ }^{2}$, Xiao Ying Liu ${ }^{2,3}$, Fritz Lai ${ }^{2}$, Xu Guang Yan², Margaret Farrelly ${ }^{2}$, Su Tang Guo ${ }^{2,4}$, Xin Han Zhao ${ }^{1}$ and Xu Dong Zhang $\mathbb{1}^{2}$

\section{Correction to: Cell Death and Disease (2018) 9: 679 https://doi.org/10.1038/s41419-018-0714-7 published online 07 June 2018}

Since publication of this paper, the authors have noticed that there were errors in Fig. 2A (the GAPDH of Mel-CV, Mel-CV.S, Mel-RMu and Mel-RMu.S), Fig. 2C (the GAPDH of Mel-CV.S and Mel-RMu.S), Fig. 3F (the GAPDH of Mel-CV.S and Mel-RMu.S), Fig. 3J (the GAPDH of Mel-RMu.S), Fig. 5C (the ERK1/2 of patient\#3(post)), and Fig. 5F (the RIP1 of Mel-CV.S and Mel-RMu.S, the GAPDH of Mel-CV and Mel-RMu). As a result of the misfiling of the data during preparation of figures, incorrect images were inadvertently inserted in these figures. The correct figures are given below. The corrections do not alter the conclusions of the paper.

The authors would like to apologize for any inconvenience this may have caused.

Published online: 05 March 2019

Correspondence: Xin Han Zhao (zhaoxinhan@mail.xitu.edu.cn) or Xu

Dong Zhang (Xu.Zhang@newcastle.edu.au)

${ }^{1}$ Department of Medical Oncology, The First Affiliated Hospital of Xi'an

Jiaotong University, Xi'an, Shaanxi 710061, China

${ }^{2}$ School of Medicine and Public Health, The University of Newcastle, Newcastle, NSW 2308, Australia

${ }^{3}$ School of Life Science, Anhui Medical University, Hefei, Anhui 230032, China

${ }^{4}$ Department of Molecular Biology, Shanxi Cancer Hospital and Institute,

Taiyuan, Shanxi 030013, China

These authors contributed equally: Fu Xi Lei, Lei Jin

Edited by: G. Dewson

(c) (i) Open Access This article is licensed under a Creative Commons Attribution 4.0 International License, which permits use, sharing, adaptation, distribution and reproduction in any medium or format, as long as you give appropriate credit to the original author(s) and the source, provide a link to the Creative Commons license, and indicate if changes were made. The images or other third party material in this article are included in the article's Creative Commons license, unless indicated otherwise in a credit line to the material. If material is not included in the article's Creative Commons license and your intended use is not permitted by statutory regulation or exceeds the permitted use, you will need to obtain permission directly from the copyright holder. To view a copy of this license, visit http://creativecommons.org/licenses/by/4.0/. 


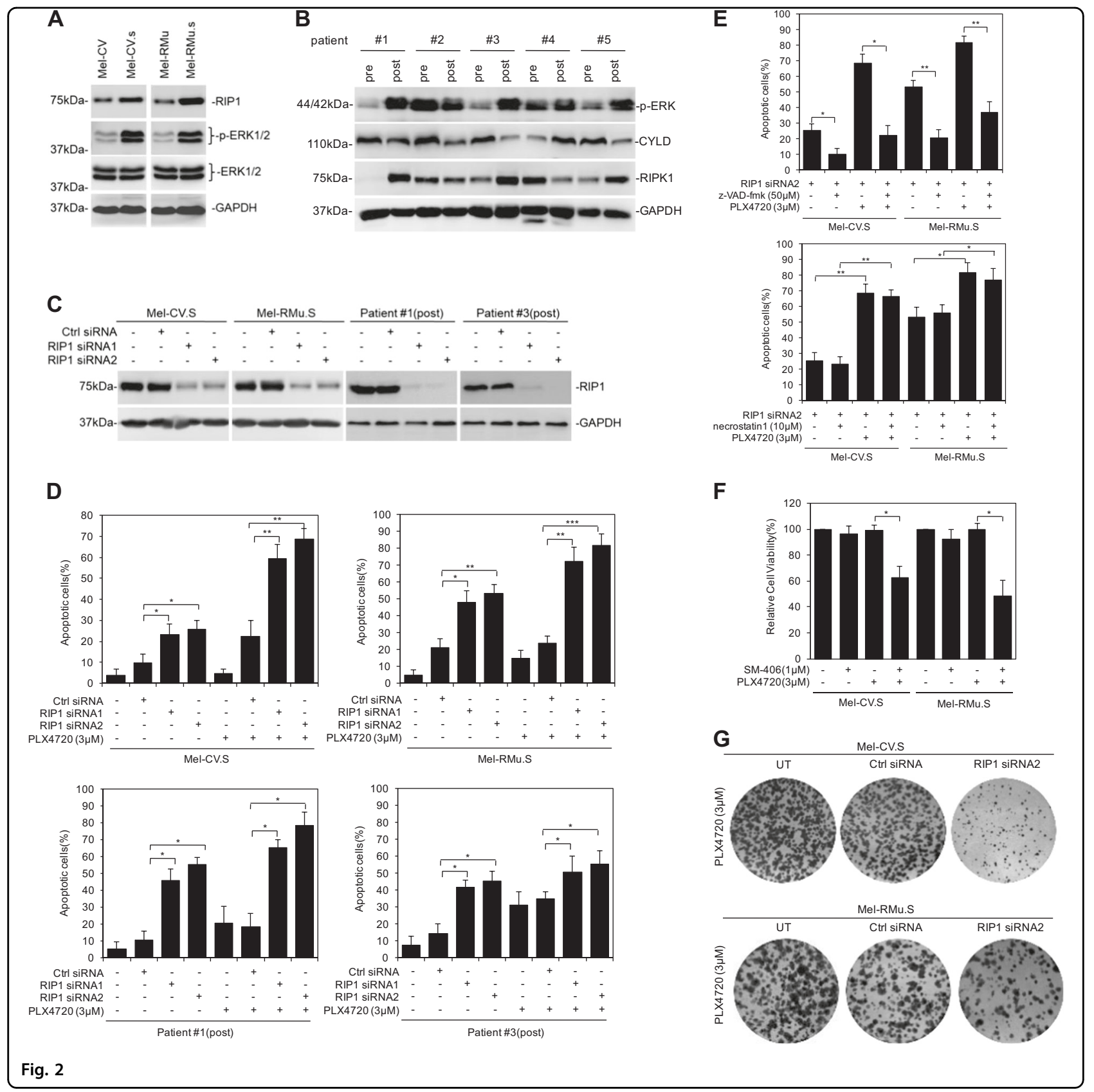




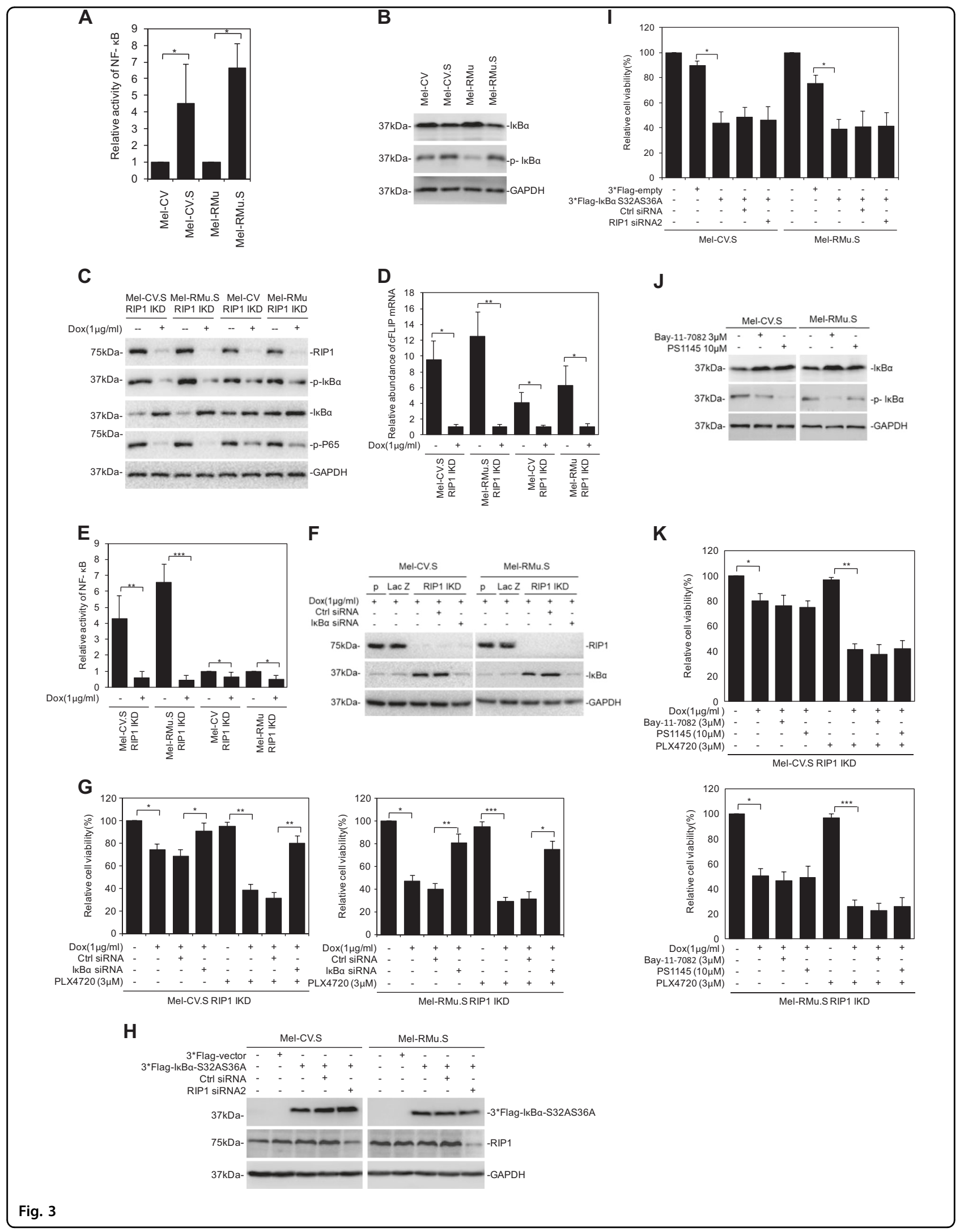




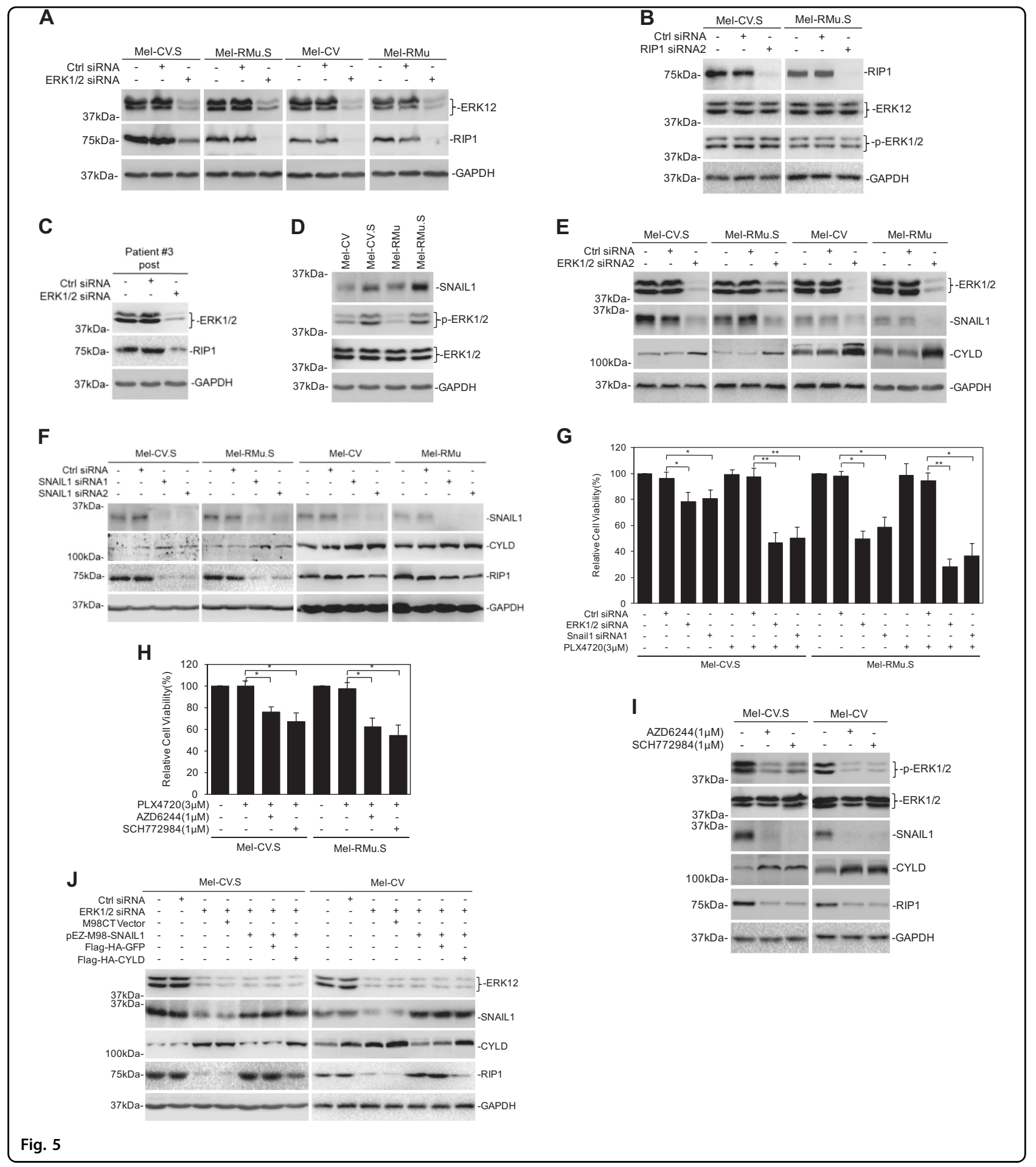

